\title{
O PROCESSO DE ENSINO-APRENDIZAGEM: INTERVENÇÕES DO PSICOPEDAGOGO NA INSTITUIÇÃO ESCOLAR
}

\author{
Edilson Raniere Gonçalves Pereira ${ }^{1}$ \\ Osmar Viveiros de Carvalho ${ }^{2}$ \\ Talita Mirella Ferreira da Silva ${ }^{3}$
}

RESUMO: A temática geral do presente estudo está na análise de como deve acontecer a integração do psicopedagogo no contexto escolar, especialmente no processo de ensinoaprendizagem, pois é fato perceber que grande parte das dificuldades de aprendizagem surgidas na relação estabelecida entre os sujeitos desse processo só podem ser identificadas e solucionadas através da atuação do psicopedagogo que, infelizmente, ainda tem pouca participação neste processo no contexto atual da educação. Destarte, este trabalho objetiva refletir sobre a atuação deste profissional frente às dificuldades de aprendizagem. Portanto, para o alcance desse objetivo realizou-se uma pesquisa bibliográfica feita através de material bibliográfico, que possibilitou a análise das visões de autores como Feldmann e Fischer (2005), Soares e Sena (2010), Kubó e Botomé (2001), Martins e Figueiredo (2011), Caetano (2012) e dentre outros, que deram embasamento ao estudo e comprovaram a efetiva influência positiva que o psicopedagogo tem dentro do ambiente escolar. Concluise o estudo apresentando que o psicopedagogo desempenha papel de grande relevância dentro da escola, diagnosticando dificuldades, apoiando sujeitos e propondo metodologias de trabalho e convívio.

Palavras-chave: Psicopedagogo. Ensino. Aprendizagem. Dificuldades. Diagnóstico.

ABSTRACT: The general theme of this study is the analysis of how the integration of the psychopedagogist in the school context should happen, especially in the teaching-learning process, as it is a fact to realize that most of the learning difficulties that arise in the relationship established between the subjects of this process only they can be identified and solved through the role of the psychopedagogist who, unfortunately, still has little participation in this process in the current context of education. Thus, this work aims to reflect on the performance of this professional in the face of learning difficulties. Therefore, to achieve this objective, a bibliographic research was carried out through books and the internet, which allowed the analysis of the views of authors such as Feldmann and Fischer (2005), Soares and Sena (2010), Kubó and Botomé (2001), Martins and Figueiredo (2011), Caetano (2012) and among others that supported the study and

\footnotetext{
I Graduado em pedagogia e Administração, especialista em Psicopedagogia clínica e institucional. Email: edilsonraniere@gmail.com

${ }^{2}$ Graduado em Ciências Biológicas - URCA, Tecnólogo em Gestão Pública - Uninabuco, Especialista em Ecologia - URCA, Especialista em Gestão Pública - Univasf. Email: osmarexu@gmail.com.br

3 Graduada em Letras e Direito, especialista em Ensino da Língua Portuguesa- URCA Email: talitamirellaiı@gmail.com
} 
proved the effective positive influence that the educational psychologist has within the school environment. The study concludes by showing that the psychopedagogist plays a very relevant role within the school, diagnosing difficulties, supporting subjects and proposing work and interaction methodologies.

KeyWords: Psychopedagogue. Teaching. Learning. Difficulties. Diagnosis.

\section{INTRODUÇÃO}

O tema do presente trabalho tem como foco central a participação ativa do psicopedagogo dentro do processo de ensino-aprendizagem no ambiente da escola. Diante dessa abordagem, é possível perceber uma problemática em torno do assunto em questão: o contexto atual da educação formal não inclui no processo de ensino-aprendizagem a presença do psicopedagogo como sujeito que intervém nesta construção. Neste sentido, abre-se um questionamento relacionado à problemática levantada acima: como o psicopedagogo pode influenciar positivamente no ato de educar dentro da escola?

Na perspectiva de respostas frente à problemática e à indagação acima, tem-se como objetivo principal da pesquisa refletir sobre a atuação do psicopedagogo frente às dificuldades de aprendizagem no processo ensino-aprendizagem, como objetivos específicos tem-se as seguintes proposições: caracterizar a figura do psicopedagogo no contexto atual, analisar de modo sistemático o processo de ensino-aprendizagem e demonstrar as formas como esse profissional pode se inserir dentro deste processo.

Este é um tema bastante relevante devido à carência de informações disponíveis, principalmente nos espaços escolares, sobre a participação do psicopedagogo no processo de ensino-aprendizagem. Além de ser um assunto que tem ganhado destaque nas últimas décadas face ao crescente surgimento dos problemas de aprendizagem desencadeados pela escola construtivista.

Portanto, o presente trabalho se justifica por sugerir a importância da psicopedagogia tanto no ensino como na aprendizagem, assim como por se tornar mais uma fonte investigativa que justifica a atuação de tal profissional dentro do ambiente escolar.

O pensamento de vários autores como Caetano (2012), Feldmann e Fischer (2005), Kubó e Batomé (200I), Martins e Figueiredo (2011), Soares e Sena (2010) e Thieser (2008) 
vão ao encontro das ideias aqui colocadas. A maioria dos autores defende uma participação ativa do psicopedagogo dentro do ensino-aprendizagem vivenciado na escola. Caetano (2012), inclusive, indica a importância do trabalho desse profissional numa perspectiva preventiva.

Pode-se facilmente verificar a importância da presença do psicopedagogo na instituição escolar e como este, como um profissional qualificado, pode contribuir e muito através das intervenções psicopedagógicos, para um trabalho preventivo, para melhores condições de aprendizagem, visando à solução dos problemas de aprendizagem neste ambiente, através de técnicas e métodos próprios, dando assistência aos professores e toda a equipe escolar. (CAETANO, 2012, p.28)

Diante do exposto acima, pode-se ter uma noção clara da importância do psicopedagogo no ambiente escolar. Evidencia-se o caráter insubstituível de sua função dentro da escola.

É importante destacar, como hipótese, que para se ter um diagnóstico preciso e um encaminhamento de soluções ou prevenção de dificuldades de aprendizagem dentro do contexto escolar é imprescindível a presença de um psicopedagogo.

\section{DESENVOLVIMENTO}

Iniciar uma análise e discussão que envolve o papel do psicopedagogo frente ao processo de ensino-aprendizagem merece, antes de tudo, uma análise das características deste profissional e de suas particularidades, assim como a evolução dos seus direitos no decorrer da história.

O psicopedagogo se caracteriza como um profissional que possui curso de pósgraduação voltado para o trabalho de investigação das dificuldades cognitivas encontradas no decorrer do processo de aprendizagem e para a formulação de estratégias que possam minimizar ou suprir estas dificuldades.

O contexto histórico ligado à formação do psicopedagogo como profissional não é extenso, basta observar, por exemplo, a sua recente difusão no cenário brasileiro , que ocorreu a partir dos anos 70, passando por inúmeras modificações.

No Brasil, a formação do psicopedagogo vem ocorrendo em caráter regular e oficial desde a década de 70 em instituições universitárias de renome. Esta formação foi regulamentada pelo Ministério da Educação e Cultura (MEC) em cursos de pós-graduação e especialização, com carga horária mínima de 36oh. O curso deve atender às exigências mínimas do Conselho Federal de Educação 
quanto à carga horária, critérios de avaliação, corpo docente e outras. Não há normas e critérios para a estrutura curricular, o que leva a uma grande diversificação na formação. (FELDMANN E FISCHER, 2005, p.2)

De acordo com a descrição acima, é possível perceber o quanto a profissão é recente no Brasil, demandando ainda muito debate. Isso fica mais evidente quando se observa a luta da classe pela regulamentação da profissão durante sua recente história no país.

O psicopedagogo normalmente pode atuar na área clínica e institucional. No que diz respeito à parte clínica, o profissional tem um aspecto mais terapêutico, pois como afirma Feldmann e Fischer (2005) o psicopedagogo, obedecendo a uma linha terapêutica, precisa identificar as dificuldades, diagnosticá-las, desenvolver soluções e conscientizar pais, escola e professores. Nesta linha de pensamento do autor, o profissional precisa fazer uma sondagem para saber as dificuldades e assim propor estratégias que viabilizem as soluções destas dificuldades.

Já no que diz respeito à atuação institucional é possível fazer um comparativo entre o pensamento de dois autores. Para Soares e Sena (2010) o psicopedagogo em sua atuação institucional, também chamada de preventiva, pode desempenhar práticas de orientação, docência e preparação dos profissionais. Numa mesma linha de pensamento, Feldmann e Fischer (2005) têm a mesma definição, porém revelando que o psicopedagogo precisa participar das relações da comunidade educativa. Ambos os autores têm visões idênticas a respeito da psicopedagogia preventiva, isso acontece porque não há outra definição mais clara do que a apresentada. Essa face da psicopedagogia se revela, dentro do ensino, como um conjunto de mecanismos que o profissional usa para se fazer presente junto ao contexto escolar na busca de soluções para as dificuldades de aprendizagem encontradas, tanto individuais quanto coletivas.

Diante do enfoque maior dado à psicopedagogia institucional, é importante explicar que a atuação do psicopedagogo dentro do ambiente escolar tem como principal intuito sua contribuição para o processo de ensino-aprendizagem. Dessa forma, é possível indagar acerca da atuação psicopedagógica dentro da escola: como o psicopedagogo pode participar ativamente do processo de ensino-aprendizagem de forma que possa contribuir para uma aprendizagem significativa do educando? 
É fato perceber que o questionamento acima é algo que define e retoma claramente o tema do presente trabalho, mas certamente uma conclusão ou uma resposta imediata a respeito deste questionamento não o deixaria claramente explícito. Antes de formalizar uma resposta, é necessário discutir como se dá o processo de ensinoaprendizagem seja ele na escola formal seja no espaço informal.

Para muitos, o conceito de processo ensino-aprendizagem parece simples, mas na verdade, numa visão mais crítica, verificam-se equívocos na sua compreensão. Um dos erros mais comuns é pensar ensino-aprendizagem e ter-se a ideia de algo restrito à instituição escolar, quando na verdade essa dinâmica pode acontecer em qualquer ambiente, desde que algo seja ensinado por um sujeito e aprendido por outro, independentemente do ambiente. Dessa forma, é preciso pensar o processo como um mecanismo de dimensões mais extensas, que perpassa o ambiente físico da escola. Por outro lado, isso não quer dizer que os conceitos ensinados e aprendidos fora da escola não possam ter influência dentro do contexto escolar, pelo contrário, apresentam grande interferência e, neste sentido, o professor, em parceria com o psicopedagogo, deve transformar essa aprendizagem externa em algo benéfico ao ensino e à aprendizagem que ocorrem dentro do ambiente escolar.

Segundo Kubó e Botomé (200I), o processo de ensino-aprendizagem pode ser definido como um complexo sistema de comportamentos que acontece entre o professor e o aluno. Quando o autor se refere a um complexo sistema, revela que não existe uma simples forma tanto para o ensino quanto para a aprendizagem, não é um sistema que se encontra pronto como, analogicamente, um programa de computador, mas se caracteriza como algo construído entre quem ensina e quem aprende. Numa visão mais futurista, é possível encontrar outros enfoques ainda mais complementares, que além de incluir o professor e o aluno, também inclui outros elementos, como é o caso de Thiesen (2008), que defende firmemente o uso da interdisciplinaridade dentro dessa dinâmica.

Diante das visões apresentadas, percebe-se o processo em questão como algo que deve satisfazer as necessidades e suprir as dificuldades de aprendizagem, pois, só assim, é possível construir um conhecimento que seja verdadeiramente significativo para o educando a discussão acima, compreende-se o psicopedagogo não como um profissional 
que tem a função de substituir o professor, mas com o papel primordial de auxílio o educador, a família e a comunidade escolar em geral.

O envolvimento do psicopedagogo, no espaço escolar, acontece principalmente devido ao constate aparecimento de dificuldades de aprendizagem, que, no contexto atual, se tornou um dos maiores dilemas da escola. Essas dificuldades surgem como consequência de diversos fatores que podem estar dentro ou fora da escola. $\mathrm{Na}$ maioria das vezes, a dificuldade de aprendizagem ocorre devido a algum distúrbio que o educando apresenta, deixando-o impossibilitado de acompanhar o nível da turma na qual está inserido. Por outro lado, é importante destacar que muitas vezes as dificuldades de aprendizagem surgem por fatores externos ao aluno, como exemplo disso, tem-se as metodologias inapropriadas usadas pelo professor, os processos de socialização excludentes e a influência das famílias. Para reforçar esse pensamento, analisemos o excerto abaixo:

\begin{abstract}
Apesar de vários estudos no Brasil, romper com problemas de aprendizagem escolar ainda é preocupante. Fatores como falta de preparo de educadores, condições precárias de funcionamento de gestão administrativa, pedagógica e estrutural da maioria das escolas; questões econômicas/ sociais e culturais das famílias, entre outros, têm servido de pauta para debates dentro e fora das escolas, responsabilizando estes fatores como causadores dos problemas de aprendizagem escolar, contribuindo assim com a falta de estímulo de alunos e professores. (MARTINS E FIGUEIREDO, 20II, p.3).
\end{abstract}

No contexto acima, percebe-se como os fatores podem ser variados quando se fala na causa que leva às dificuldades de aprendizagem. Já numa visão mais tecnicista, Caetano (2012) acredita que tais dificuldades ocorrem devido a uma disfunção do sistema nervoso. De fato, existem inúmeras dificuldades que são originadas por distúrbios gerados por essas disfunções, mas é importante verificar que ,muitas vezes, estas podem ter se originado justamente por fatores presentes no ambiente do educando. De qualquer forma, Caetano (2012) foi lúcido no seu pensamento, pois revela, mesmo de forma indireta, a importância do psicopedagogo no processo de ensino-aprendizagem.

$\mathrm{Na}$ verdade, as dificuldades de aprendizagem trouxeram para a escola mais um problema que não pode ser resolvido apenas pelo professor, que, muitas vezes, se torna o principal sujeito responsável pelo surgimento destas limitações no aluno, mas necessita que toda a comunidade escolar esteja preparada na tentativa de solucionar este problema. De acordo com Feldmann (2005) as escolas estão numa situação desafiadora, pois se 
sentem preocupadas com os alunos que têm dificuldades, mas em contrapartida não possuem uma política de intervenção que possa suprir essas dificuldades. No entanto, como resposta a esse problema o autor considera:

Neste contexto, o psicopedagogo institucional, como um profissional qualificado, está apto a trabalhar na área da educação, dando assistência aos professores e a outros profissionais da instituição escolar para melhoria das condições do processo ensino-aprendizagem, bem como para prevenção dos problemas de aprendizagem. (FELDMANN E FISCHER, 2005, p.4)

O ponto central da presente discussão está em torno do pensamento citado acima. Devido à complexidade que têm apresentado nas últimas décadas, as dificuldades de aprendizagem não podem ser investigadas, diagnosticadas e solucionadas sem a presença do psicopedagogo dentro do espaço escolar. Nesse contexto, surge a necessidade desse profissional participar ativamente do processo de ensino-aprendizagem, de maneira que possa colaborar significativamente para a solução de problemas encontrados dentro dessa dinâmica.

Há inúmeras visões construtivistas que defendem a participação ativa do psicopedagogo dentro da escola, contribuindo para que esta idéia se torne mais concreta.

A psicopedagogia é uma área que estuda e lida com o processo de aprendizagem e com os problemas dele decorrentes. Acreditamos que, se existissem nas escolas psicopedagogos trabalhando com essas dificuldades, o número de crianças com problemas seria bem menor. (FELDMANN E FISCHER, 2005, p.4)

Comparando a visão acima com o pensamento de Martins e Figueiredo (20II), identificam-se particularidades, pois na visão destes últimos, a psicopedagogia permite que os educadores desempenhem melhor a sua prática pedagógica. Desta forma, os autores reforçam a ideia posta por Feldmann e Fischer (2005) na defesa desse profissional dentro da escola.

A Psicopedagogia, como a área que estuda o processo ensino-aprendizagem, pode contribuir com a escola na missão de resgate do prazer no ato de aprender e da aprendizagem nas situações prazerosas. (CAETANO, 2012, p.23)

Diante de todas as visões apresentadas, diz-se que a psicopedagogia se configura como um elemento essencial dentro da escola ou mais precisamente dentro do processo de ensino-aprendizagem. Nesse processo, é claro perceber que existem duas faces - ensino e 
aprendizagem- que necessitam da participação do psicopedagogo para que possam acontecer. De um lado é possível encontrar o ensino que tem como representante o professor com suas metodologias, seus comportamentos, sua formação e os objetivos que almeja alcançar, portanto, diante dessa face, o psicopedagogo precisa se fazer presente e saber direcionar, junto ao professor, as soluções para as possíveis dificuldades dos educandos. Na sua tarefa de parceria com o educador, o psicopedagogo precisa inicialmente investigar a metodologia adotada pelo professor para a execução de atividades em sala de aula e, caso verifique possíveis falhas que atrapalham na aprendizagem do educando, ele precisa propor novas estratégias ao docente, que possam beneficiar todos os estudantes. Isso não é algo irregular, tampouco invasivo, pois a função do psicopedagogo, nesse caso, não é denegrir ou acusar o educador por suas estratégias didáticas mal sucedidas, mas fornecer, através desta investigação, um diagnóstico preciso do resultado das metodologias usadas pelo educador, ajudando-o a adequá-las de modo que possa fornecer uma aprendizagem verdadeiramente significativa ao educando. Esse fator é primordial dentro do processo de ensino-aprendizagem, porque o professor está em constante contato com o aluno e precisa estar preparado para suprir todas as necessidades destes, em vez de causarlhes mais transtornos. Esta ideia é retratada com maior firmeza na visão de Martins e Figueiredo (2011, p.4):

No processo educacional o papel de quem ensina e de como se aprende é fator importantíssimo para que professores e alunos criem vínculos indispensáveis para a aprendizagem. Este processo precisa ser construído de maneira sócio interacionista, pois ensinar e aprender envolvem o professor, o aluno e o meio onde se dá a aprendizagem.

A maneira como o professor e o aluno se relaciona precisa ser pensada e o psicopedagogo é um dos sujeitos que pode colaborar positivamente nesta relação. Apesar de o professor representar um dos principais sujeitos do ensino, senão o principal, ele não é o único dentro desse processo, existe, em outro extremo, a escola que também tem sua parcela de responsabilidade. Nessa perspectiva, o psicopedagogo deve nortear a escola na execução da sua função, pois para que o professor possa executar uma metodologia apropriada é necessário ter apoio da escola, portanto, o psicopedagogo entra nessa relação no intuito de, junto com a equipe escolar, garantir os recursos e o apoio necessários ao 
professor, além de servir como mediador da relação entre a escola e os demais sujeitos envolvidos no processo de ensino-aprendizagem.

Numa reflexão mais crítica sobre a influência do psicopedagogo no fenômeno ensino-aprendizagem, é possível analisar sua importância na aprendizagem. Assim como pode auxiliar o professor e a escola, o psicopedagogo tem fundamental participação na aprendizagem do educando, contribuindo para que as dificuldades sejam prevenidas ou superadas.

Frente aos problemas de aprendizagem surgidos no ambiente escolar, o psicopedagogo precisa inicialmente fazer uma sondagem para diagnosticar a causa desses problemas que podem estar associados a distúrbios neurológicos, assim como ligados à didática do professor, a fatores escolares ou extra escolares. Para cada situação é necessário um posicionamento diferente desse profissional, pois cada situação se distingue por sua natureza e características.

Diante de um distúrbio neurológico que causa dificuldades ao aluno no momento de aprender, o psicopedagogo necessita identificar de qual distúrbio se trata, bem como sua causa, para que possa indicar o melhor direcionamento. É importante destacar que, nesse caso, a ajuda de outros profissionais, como o psicólogo, podem ser de grande valia na identificação do problema. No caso de não conseguir constatar ou então, mesmo que constate, o problema não seja da sua área de atuação, é dever do psicopedagogo encaminhar o caso para outros profissionais habilitados. Sobre isso Feldmann (2005) afirma que o psicopedagogo precisa, quando necessário, encaminhar o aluno para outros profissionais como psicólogo, fonoaudiólogo, neurologista e dentre outros. Por outro lado, se a situação não se estende a problemas físicos é necessário que o profissional esteja preparado para solucionar as dificuldades surgidas na sala de aula, auxiliando os educadores para a adaptação de atividades quando identificar algum distúrbio de aprendizagem, propondo estratégias que permitam que aqueles educandos que apresentam dificuldades também possam ter uma aprendizagem significativa. Porém, a psicopedagogia não se faz necessária apenas face a casos especiais dentro da sala de aula, mas pode contribuir de forma decisiva na aprendizagem de todos os alunos. Segundo Martins e Figueiredo (20II), o trabalho do psicopedagogo pode minimizar os problemas de aprendizagem daqueles alunos que têm 
dificuldades de aprendizagem, assim como dos alunos considerados "normais" perante a escola. Essa afirmação ganha validade quando se percebe que a psicopedagogia não é apenas uma área de solução de adversidades, mas também de prevenção destas.

É inegável que o envolvimento psicopedagógico dentro do processo de ensinoaprendizagem é de extrema importância, mas essa atuação não deve ocorrer apenas no espaço restrito da escola, pois a criança também adquire conhecimentos fora desse ambiente, e uma das instituições que mais transmite conhecimento é a família.

Dessa forma, o psicopedagogo precisa estar em parceria com essa instituição, orientando-a para que ela possa ajudar de modo eficiente na superação de dificuldades.

O que a família pensa, seus anseios, seus objetivos e expectativas com relação ao desenvolvimento de seu filho também são de grande importância para o psicopedagogo chegar a um diagnóstico. (FELDMANN E FISCHER, 2005, p.6).

A família pode ser também a responsável pelo surgimento de problemas de aprendizagem no educando, nesse sentido é inevitável que o psicopedagogo crie laços com essa instituição para que possa nortear seu trabalho.

De modo geral, não é fácil articular positivamente todas as instituições que fazem parte do processo ensino-aprendizagem, mas esse é um dos principais papéis do psicopedagogo na busca de um ensino mais dinâmico e prazeroso e de uma aprendizagem mais significativa para o educando

\section{CONSIDERAÇÕES FINAIS}

É notório perceber que o psicopedagogo ainda tem muito a conquistar na sua área de atuação, mas esse é um desafio que pode ser vencido através da comprovação da relevante importância da psicopedagogia para o processo de ensino-aprendizagem, que é entendido como algo que vai além do espaço escolar e, por isso, necessita da participação de um sujeito capaz de propor soluções para adversidades causadas, muitas vezes, pelos próprios sujeitos que compõem esse processo.

A partir do que foi exposto durante o trabalho, é possível concluir que a participação desse profissional no processo ensino-aprendizagem é de total importância. As dificuldades de aprendizagem são problemas cada vez mais recorrentes na escola, mas 
que podem ser superadas ou mitigadas com os direcionamentos dados pelo psicopedagogo, sujeito preparado para tal desafio no cenário escolar.

Destarte, o psicopedagogo, como figura integrante do processo ensinoaprendizagem, necessita identificar e entender os sujeitos envolvidos no ato de educar e, dessa forma, propor estratégias a cada um, no sentido de prevenir ou solucionar distúrbios e dificuldades de aprendizagem.

\section{REFERÊCIAS BIBLIOGRÁFICAS}

CAETANO, Miria. O assessoramento do psicopedagogo na instituição escolar. 2012. $32 \mathrm{f}$. Trabalho de Conclusão de Curso (Especialização em psicopedagogia)- universidade Tuiuti do Paraná, Curitiba, 2012. Disponível em: < http://tcconline.utp.br/wpcontent/uploads/2012/o8/O-ASSESSORAMENTO-DO-PSICOPEDAGOGO-NAINSTITUICAO-ESCOLAR.pdf > Acesso em: 5 ago. 202I.

FELDMANN, Juliane; FISCHER, Julianne. A importância do psicopedagogo dentro da instituição escolar. Disponível em: < https://docplayer.com.br/925844I-A-importancia-dopsicopedagogo-dentro-da-instituicao-escolar.html > Acesso em: io jun. 202I.

KUBO, Olga Mitsue; BOTOMÉ, Sílvio Paulo. Ensino-aprendizagem: uma interação entre dois processos comportamentais. Disponível em: < http://www.lce.esalq.usp.br/arquivos/aulas/2012/LCE5870/Kubo\%20e\%20Botome\%20Pro \%2oPedro.pdf > Acesso em: 13 jun. 2021.

MARTINS, Marlene Nunes; FIGUEIREDO, Lília Márcia de Souza. Um olhar psicopedagógico sobre dificuldades de aprendizagem. Revista científica eletrônica de ciências sociais aplicadas da Eduvale, Jaciara, Ano IV, $\mathrm{n}^{\circ}$ o6, I-II, novembro, 2011. Disponível em: < http://www.eduvalesl.edu.br/site/edicao/edicao-55.pdf > Acesso em: I5 jun. 2021. 
SOARES, Matheus; SENA, Clério Cezar Batista. A contribuição do psicopedagogo no contexto escolar. Disponível em: < http://www.abpp.com.br/sites/default/files/r26.pdf > Acesso em: Io jun. 2021.

THIESE, Juares da Silva. A interdisciplinaridade como um movimento articulador no processo ensino-aprendizagem. Revista Brasileira de Educação, v. I3, n. 39, p. I-I2, set./dez., 2008. Disponível em: < http://www.scielo.br/pdf/rbedu/vi3n39/ro.pdf > Acesso em: I5 ago. 2021. 